\title{
Person to Person Biological Heat Bypass During EVA Emergencies
}

\author{
Victor S. Koscheyev, Gloria R. Leon, Joo-Young Lee, Jung-Hyun Kim, Anna Berowski, \\ University of Minnesota \\ Robert C. Treviño \\ NASA Johnson Space Center
}

\begin{abstract}
During EVA and other extreme environments, mutual human support is sometimes the last way to survive when there is a failure of the life support equipment. The possibility to transfer a coolant to remove heat or a warming fluid to increase heat from one individual to another to support the thermal balance of the individual with system failure was assessed. The following scenarios were considered: 1. one participant has a cooling system that is not working well and already has a body heat deficit equal to $100-120 \mathrm{kcal}$ and a finger temperature decline to $25^{\circ} \mathrm{C} ; 2$. one participant has the same status of overcooling and the other mild overheating. Preliminary findings showed promise in using such sharing tactics to extend the time duration of survival in extreme situations when there is a high metabolic rate in the donor.
\end{abstract}

\section{INTRODUCTION}

In considering the protection of astronauts during planetary exploration, a situation could arise in which there is a failure of an astronaut's life support system. Rapid support is crucial, particularly if the astronaut is at some distance from the habitat or space ship. Mutual support may be the only option for survival; there is a precedent for this procedure, for example, when mountain climbers share the same oxygen breathing mask to survive in the combination of hypoxia and a cold environment, or divers share breathing apparatus. The possibility was assessed that by means of specially designed files, each space suit could be interconnected with the space suit of a near-by astronaut to avoid serious consequences in this life-threatening situation. In order to evaluate whether such system design is feasible, the possibility to transfer a coolant to remove heat or a warming fluid to increase heat from one individual to another was examined. Estimates were also made on the required resources of air and minimal amount of water in the cooling/warming system able to provide the life support of two astronauts from a single life support system. Also examined was the possibility to share only metabolic heat which for one participant, is still at a comfort level, thus extending the time in which one can survive in an extreme environment until help arrives.

A physiological approach was used to explore a method for optimizing human survival in extreme cold conditions by means of sharing heat between body parts. There are few data in the literature that serve as a foundation/background for this particular paradigm. Previous studies by the present research group focused on demonstrated that finger 
comfort in cold conditions can be supported by the delivery of heat from the head to the hands through water circulating within a tubing bypass in a liquid cooling/warming garment (Koscheyev, Leon, Coca, \& Treviño, 2005). Carrying this notion a step further, this pilot study/probe evaluated whether body heat can be shared from one person to another when one individual has a body heat deficit and the other is in either thermal comfort or mild overheating. Two scenarios were considered: 1. one subject's cooling/warming system is not working properly and the individual is in heat deficit while the other subject is at a thermal comfort level; 2 . one subject is at the same level of heat deficit as in Scenario 1, and the other subject is in a state of mild overheating after moderate exercise.

\section{Method}

\section{Subjects}

Two females participated in this study. Subject characteristics are shown in Table 1. Both were nonsmokers and free of medications. Subject A was the Recipient, and Subject B the Donor.

Table 1. Anthropometric characteristics of subjects

\begin{tabular}{|c|c|c|c|c|c|c|c|c|}
\hline Subject & Sex & $\begin{array}{l}\text { Age } \\
(\mathrm{yr})\end{array}$ & $\begin{array}{l}\text { Height } \\
\text { (m) }\end{array}$ & $\begin{array}{l}\text { Weigh } \\
\mathrm{t}(\mathrm{kg})\end{array}$ & $\begin{array}{l}\text { BSA } \\
\left(\mathrm{m}^{2}\right)^{\mathrm{a})}\end{array}$ & $\mathrm{BMI}^{\mathrm{b})}$ & $\begin{array}{l}\text { Body fat } \\
(\% \mathrm{BF})^{\mathrm{c})}\end{array}$ & $\begin{array}{c}\text { Body } \\
\text { density } \\
(\mathrm{g} / \mathrm{ml}) \mathrm{d})\end{array}$ \\
\hline A & $\mathrm{F}$ & 24 & 1.70 & 60.1 & 1.70 & 20.8 & 19.5 & 1.0544 \\
\hline B & $\mathrm{F}$ & 23 & 1.79 & 70.8 & 1.89 & 22.1 & 22.9 & 1.0466 \\
\hline
\end{tabular}

\section{Experimental equipment}

A plastic tubing shortened liquid cooling/warming garment, (the MACS-Delphi) through which water circulated was used in this research and worn over briefs and bra. The garment covered the total body surface except for the face, the hands, the calves and feet. The garment was composed of cotton/polyester spandex fabric; the tubing system was sewn onto the fabric. The tubing diameter was ID $2.8 \mathrm{~mm}$ and OD $4.5 \mathrm{~mm}$ (TYGON R TUBING AAC02641-CP, COLE-PARMER, USA). The garment characteristics are shown in Table 2.

Table 2. Characteristics of MACS-Delphi liquid cooling/warming garment

\section{Subject A Subject B}

(Garment size: Small)

\begin{tabular}{lcc}
\hline Total length of tubing $(\mathrm{m})$ & 47.12 & 75.27 \\
\hline Surface area covered by tubing $\left(\mathrm{m}^{2}\right)$ & 0.3331 and 19.6 & 0.5321 and 28.2 \\
\hline
\end{tabular}


and percentage of BSA (\%)

Flow rate $(\mathrm{ml} / \mathrm{min})$

Average 556

A small water bath (model No. MRC150DH2-HT-DV, MELCOR Corporation, USA) controlled the temperature of the water and provided stability of the flow rate at 1.9 liter/min. Temperature sensors inserted in the tubing inlet/outlets of the LCWG controlled the designated temperature of the circulating water. The water temperature regimes imposed had an accuracy of $\pm 0.2^{\circ} \mathrm{C}$. Water temperature was also monitored by means of a data acquisition program displayed on the computer screen.

\section{Measurements}

Heat exchange was controlled by monitoring skin and core temperature. For Subject A (Recipient), thermal sensors (model 409A; YSI, Yellow Springs, OH) were placed on the body surface, symmetrically distributed on sites on the left and right sides of the body as follows: forehead, cheek, earlobe, neck, chest, finger, axilla, thigh, femoralis, calf, and toe. Finger $\left(T_{\text {fing }}\right)$ and toe $\left(T_{\text {to }}\right)$ temperature sensors were placed, on the mid-lateral distal phalanx of the fourth finger of each hand, and on the mid-lateral proximal phalanx of the third toe of each foot. Core temperature $\left(\mathrm{T}_{\mathrm{c}}\right)$ was estimated by measurement of rectal temperature $\left(\mathrm{T}_{\mathrm{re}}\right)$ using a temperature probe (model 401; YSI) inserted $13 \mathrm{~cm}$ into the rectum. For subject $\mathrm{B}$ (Donor), rectal, earlobe, finger and toe temperatures were monitored. A customized Labview data acquisition system summarized temperature data at $44 \mathrm{sec}$ intervals. Overall body thermal sensation and thermal comfort were assessed by ratings on individual point-scales.

\section{Calculation}

Based on [Eq. 1], heat flow was calculated. Weighted mean of skin temperature based on Hardy and DuBois 7-points equation and heat storage were calculated according to [Eq. 2] [Eq. 4].

$$
\text { Heat flow }(\mathrm{kcal} / \mathrm{min})=\mathrm{m}_{\mathrm{w}} \mathrm{C}_{\mathrm{w}}\left(\mathrm{T}_{\mathrm{in}}-\mathrm{T}_{\text {out }}\right) \text {-----------------------[Eq. 1] }
$$

Where, $\mathrm{m}_{\mathrm{w}}$ : Water flow rate $\left(1 \cdot \mathrm{min}^{-1}\right) ; \mathrm{C}_{\mathrm{w}}$ : The specific heat of water, $1 \mathrm{kcal} \cdot \mathrm{kg}^{-1} \cdot{ }^{-1} ; \mathrm{T}_{\text {in }}$ : The inlet temperature ( $) ; \mathrm{T}_{\text {out }}$ : The outlet temperature ( )

$$
\text { Mean } \mathrm{T}_{\text {sk }}=0.07 \times \mathrm{T}_{\text {head }}+0.35 \times \mathrm{T}_{\text {trunk }}+0.14 \times \mathrm{T}_{\text {arm }}+0.05 \times \mathrm{T}_{\text {hand }}+0.19 \times \mathrm{T}_{\text {thigh }}+0.13 \times \mathrm{T}_{\text {calf }}+0.07 \times \mathrm{T}_{\text {foot }}---- \text { [Eq. 2-1] }
$$

Mean $\mathrm{T}_{\text {sk corrected }}=0.07 \times\left[\left(\right.\right.$ Cheek $_{\mathrm{L}, \mathrm{R}}+$ Carotid $_{\mathrm{L}}+$ Forehead $_{\mathrm{L}, \mathrm{R}}+$ Earlobe $\left.\left._{\mathrm{L}, \mathrm{R}}\right) / 7\right]+0.35 \times\left[\left(\right.\right.$ Scrotum $_{\mathrm{R}}+$ Chest $\left.\left._{\mathrm{L}, \mathrm{R}}\right) / 3\right]+$ $0.14 \times\left[\left(\right.\right.$ Armpit $\left.\left._{\mathrm{L}, \mathrm{R}}\right) / 2\right]+0.05 \times\left[\left(\right.\right.$ Finger $\left.\left._{\mathrm{LR}}\right) / 2\right]+0.19 \times\left[\left(\right.\right.$ Thigh $_{\mathrm{L}, \mathrm{R}}+$ Femoralis $\left.\left._{\mathrm{L}, \mathrm{R}}\right) / 4\right]+0.13 \times\left[\left(\mathrm{Calf}_{\mathrm{L}, \mathrm{R}}\right) / 2\right]+$ $0.07 \times\left[\left(\right.\right.$ Toe $\left.\left._{\mathrm{L}, \mathrm{R}}\right) / 2\right]-----[$ Eq. 2-2] 
Mean body temperature $\left(\overline{\mathrm{T}}_{\mathrm{b}}\right)=0.8 \mathrm{~T}_{\mathrm{re}}+0.2 \overline{\mathrm{T}}_{\mathrm{sk}}----[\mathrm{Eq} .3]$

Heat storage $(\mathrm{kcal} / \mathrm{hr})=\Delta \overline{\mathrm{T}}_{\mathrm{b}} \times$ Body weight $(\mathrm{kg}) \times$ Specific heat of human body $\left(0.83 \mathrm{kcal} / \mathrm{kg} .{ }^{\circ} \mathrm{C}\right)---[\mathrm{Eq} .4]$

\section{Procedure}

The study consists of two conditions: No Exercise and Moderate exercise.

\section{Condition 1: No exercise}

Both subjects were studied in an environmental chamber $\left(24^{\circ} \mathrm{C}\right.$, humidity $\left.22 \%\right)$ at rest, seated in an arm chair, and donned in the MACS-Delphi. During Stage 1, Subject A Recipient was chilled by inlet water temperature at $15^{\circ} \mathrm{C}$ while Subject B Donor was warmed by inlet water temperature at $33^{\circ} \mathrm{C}$ circulating through the garment. When the Recipient reached a finger temperature (Tfing) of $26 \sim 27^{\circ} \mathrm{C}$, the tubing from the Donor's garment was connected to the Recipient's garment through a water bath, as shown in Fig. 2 . When the water temperature in the water bath began to decrease after showing a plateau, Stage 2 was terminated.

\section{Condition 2: Moderate exercise}

The Comfort and Exercise conditions were evaluated on separate days in the same environmental chamber as in Condition 1. Stage 1 chilling of the Recipient was the same as in Condition 1. The Donor ran on a treadmill at a work rate of approximately $50 \%$ of Target Heart Rate (THR). When the either the Recipient reached a criterion of Tfing $26 \sim 27^{\circ} \mathrm{C}$ or the Donor's Tre reached approximately $38^{\circ} \mathrm{C}$, the Donor terminated running. At this point, the garment tubing from the Donor was connected to the garment tubing of Recipient as shown in Fig. 1, and then both subjects sat down.

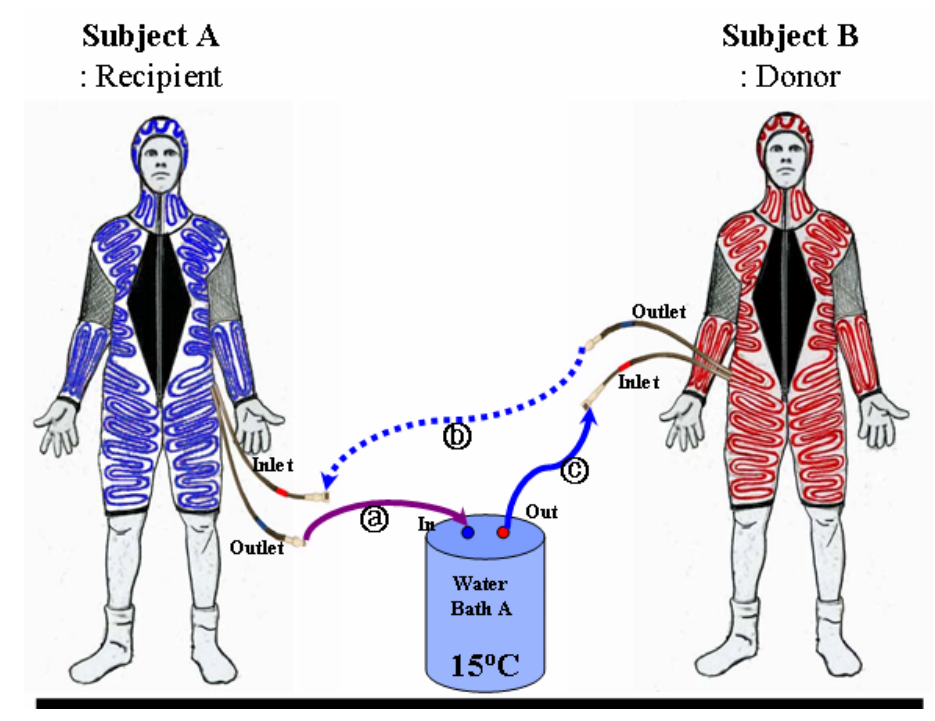

Fig. 1. Thermal bypass and the direction of the tubing between two persons, DonorRecipient.

\section{RESULTS}


Table 3 presents a summary of the heat transfer between the Donor and the Recipient in Conditions 1 and 2.

Table 3. Body heat exchange between Donor and Recipient

\begin{tabular}{|c|c|c|c|c|c|c|c|c|}
\hline \multirow[b]{3}{*}{ kcal } & \multicolumn{4}{|c|}{$\begin{array}{l}\text { Condition } 1 \\
(80 \text { min rest })\end{array}$} & \multicolumn{4}{|c|}{$\begin{array}{l}\text { Condition } 2 \\
\text { ( } 24 \mathrm{~min} \mathrm{rest} / 9 \mathrm{~min} \text { exercise) }\end{array}$} \\
\hline & \multicolumn{2}{|c|}{$\begin{array}{l}\text { Stage 1 } \\
\text { (Recipient } \\
\text { cooling; Donor } \\
\text { comfort) }\end{array}$} & \multicolumn{2}{|c|}{$\begin{array}{l}\text { Stage } 2 \\
\text { (Heat Sharing) }\end{array}$} & \multicolumn{2}{|c|}{$\begin{array}{l}\text { Stage 1 } \\
\text { (Recipient } \\
\text { cooling; Donor- } \\
\text { Exercise) }\end{array}$} & \multicolumn{2}{|c|}{$\begin{array}{l}\text { Stage } 2 \\
\text { (Heat Sharing) }\end{array}$} \\
\hline & $\begin{array}{l}\text { Total } \\
69 \mathrm{~min}\end{array}$ & $\begin{array}{l}\text { Per/ } \\
\text { min }\end{array}$ & $\begin{array}{l}\text { Total } \\
11 \mathrm{~min}\end{array}$ & $\begin{array}{l}\text { Per/ } \\
\text { min }\end{array}$ & $\begin{array}{l}\text { Total } \\
24 \mathrm{~min}\end{array}$ & $\begin{array}{l}\text { Per/ } \\
\text { min }\end{array}$ & $\begin{array}{l}\text { Total } \\
9 \mathrm{~min}\end{array}$ & $\begin{array}{l}\text { Per/ } \\
\text { min }\end{array}$ \\
\hline Recipient & -104.8 & -1.52 & & & -106.3 & -4.4 & -12.0 & -1.3 \\
\hline $\begin{array}{l}\text { Donor } \\
\text { Recipient }\end{array}$ & 8.23 & 0.12 & & & 28.2 & 1.18 & -9.0 & -1.0 \\
\hline $\begin{array}{l}\text { Donor Heat } \\
\text { Sharing }\end{array}$ & & & -59.6 & -5.42 & & & -21.0 & -2.3 \\
\hline
\end{tabular}

\section{Condition 1}

\section{Heat flow}

Figure 2 demonstrates the quantity of heat transfer from the Donor to the Recipient through Stages 1-2.

Delete Top portion re. water bath, and change $\mathrm{CN}$ to $\mathrm{R}$ 


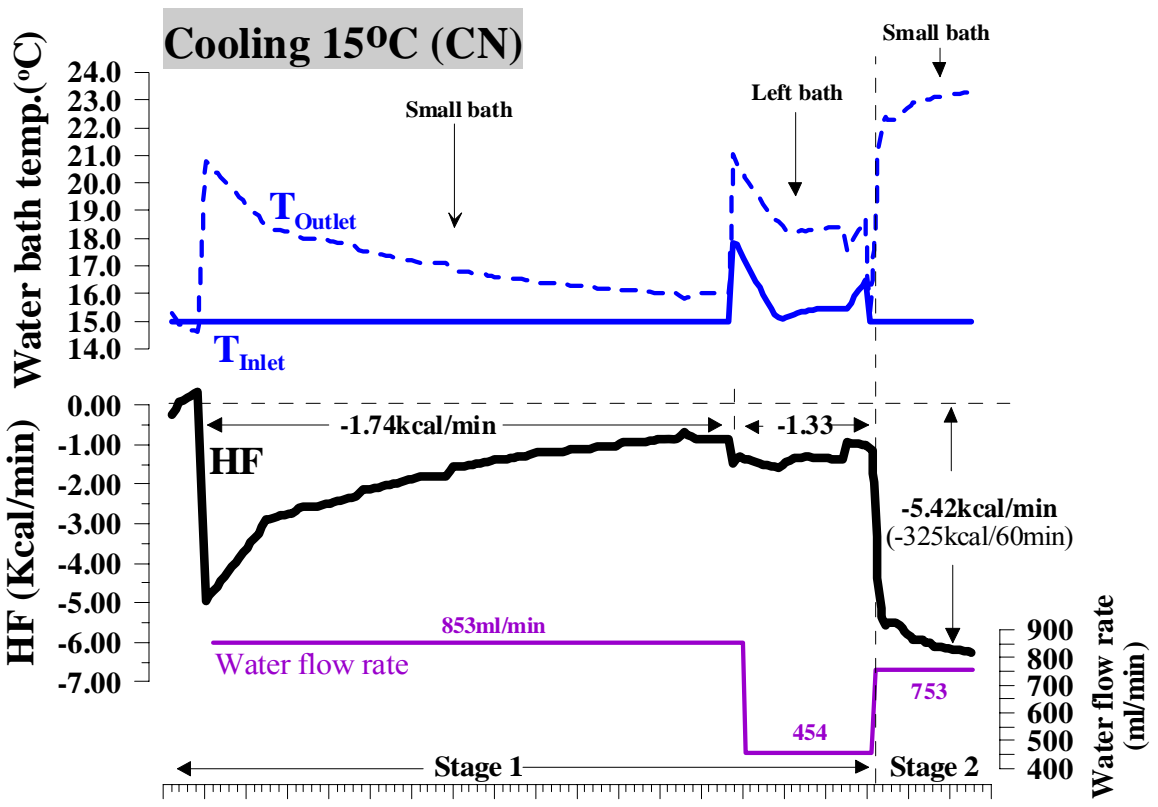

0 5101520253035404550556065707580859095100

Time(min)

Fig. 2. Heat flow and water flow rate of Recipient garment.

\section{Core temperature}

The $\mathrm{T}_{\mathrm{re}}$ dynamic of the Recipient shows a lack of stabilization in the period of heat sharing. The temperature dynamic continues to decrease $-0.0045^{\circ} \mathrm{C} / \mathrm{min}$ (Stage 2) as compared to $-0.0017^{\circ} \mathrm{C} / \mathrm{min}$ in Stage 1 . Donor $\mathrm{T}_{\mathrm{re}}$ exhibits relative stability across stages.

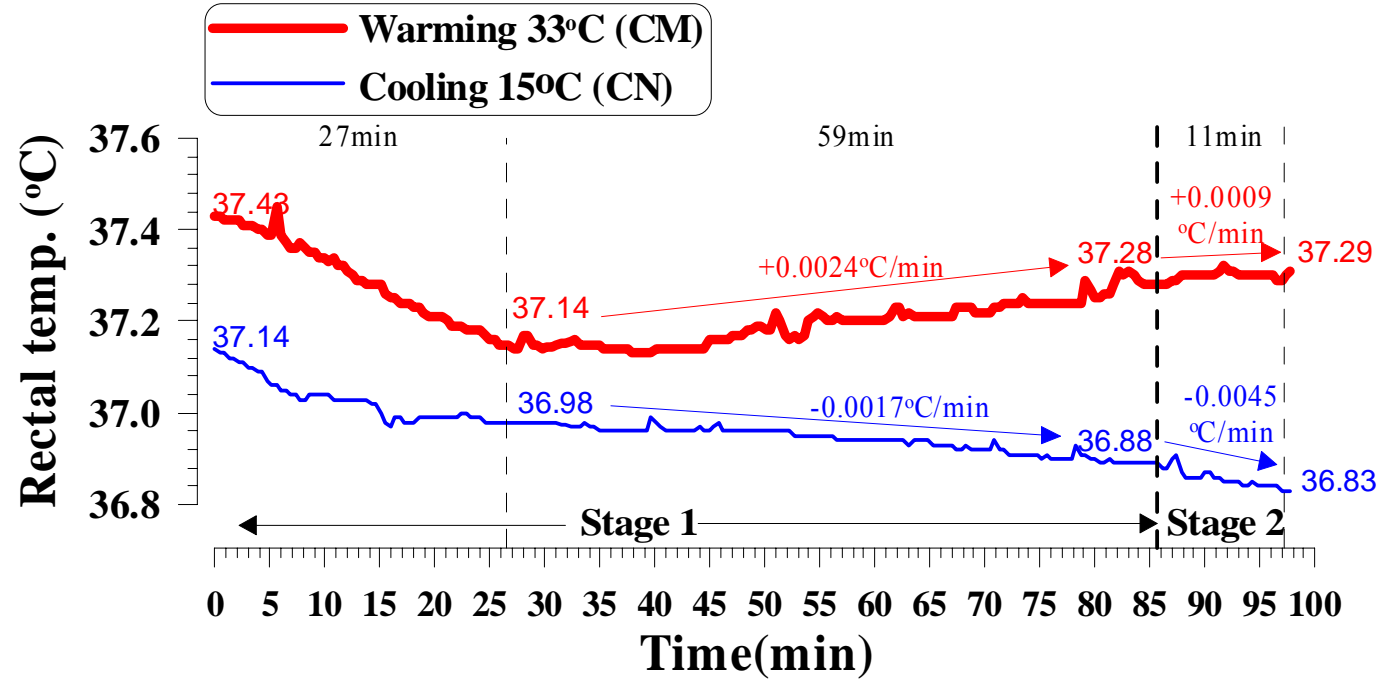

Fig. 3. Rectal temperature $\left(\mathrm{T}_{\mathrm{re}}\right)$ dynamic of Recipient and Donor across stages. (Identify which is which by $\mathrm{R}$ and $\mathrm{D}$ ) 


\section{Finger temperature}

As with $\mathrm{T}_{\mathrm{re}}$, a simialr dynamic is evident with $\mathrm{T}_{\text {fing }}$; in Stage 2 both subjects show a decrease in $\mathrm{T}_{\text {fing }}$ when they are attached to a common water file.

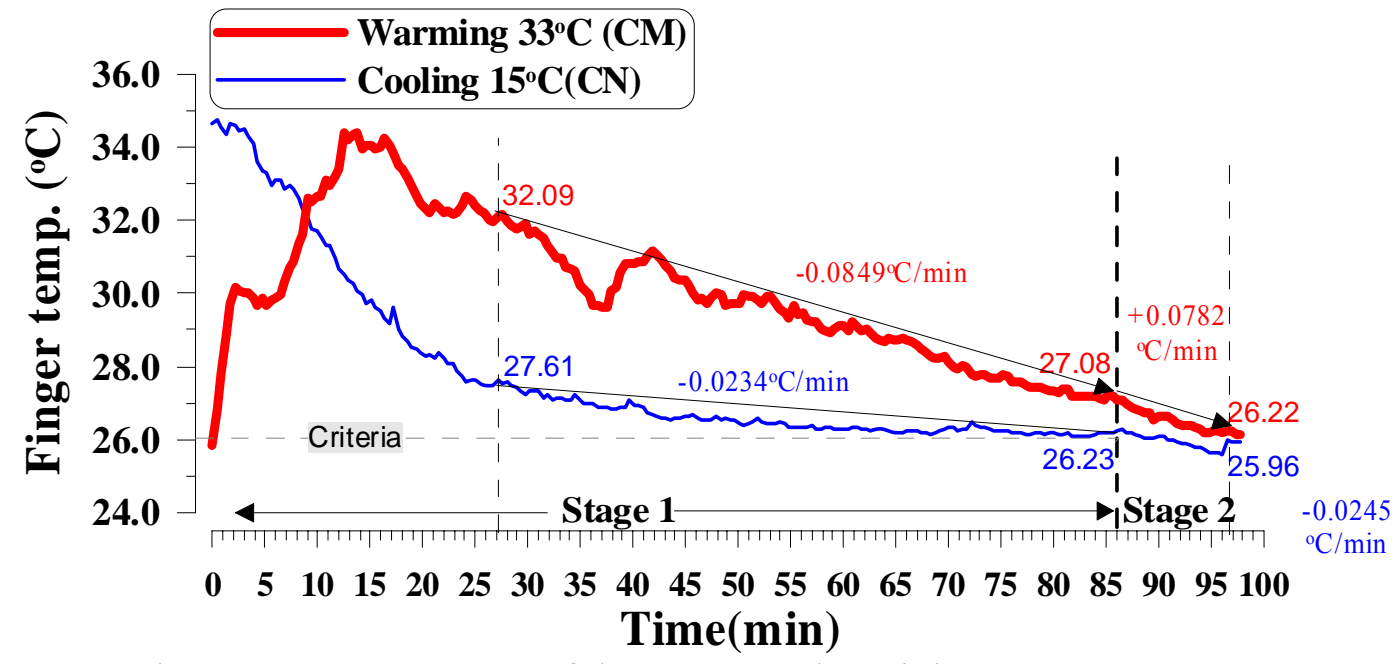

Fig. 4. Finger temperature $\mathrm{T}_{\text {fing }}$ of the Donor and Recipient across stages. Change $\mathrm{CM}$ and $\mathrm{CN}$ to $\mathrm{D}$ (donor) and $\mathrm{R}$ (recipient)

\section{Skin temperatures}

Simultaneously, local skin temperature dynamics of the Recipient exhibit obvious restoration (improvement) under the influence of the circulating water of the resting Donor. For example, the temperature indices for the earlobe and carotid areas increased by $0.2-0.4^{\circ} \mathrm{C}$ (Figure 5$)$.

Delete upper 4 lines 


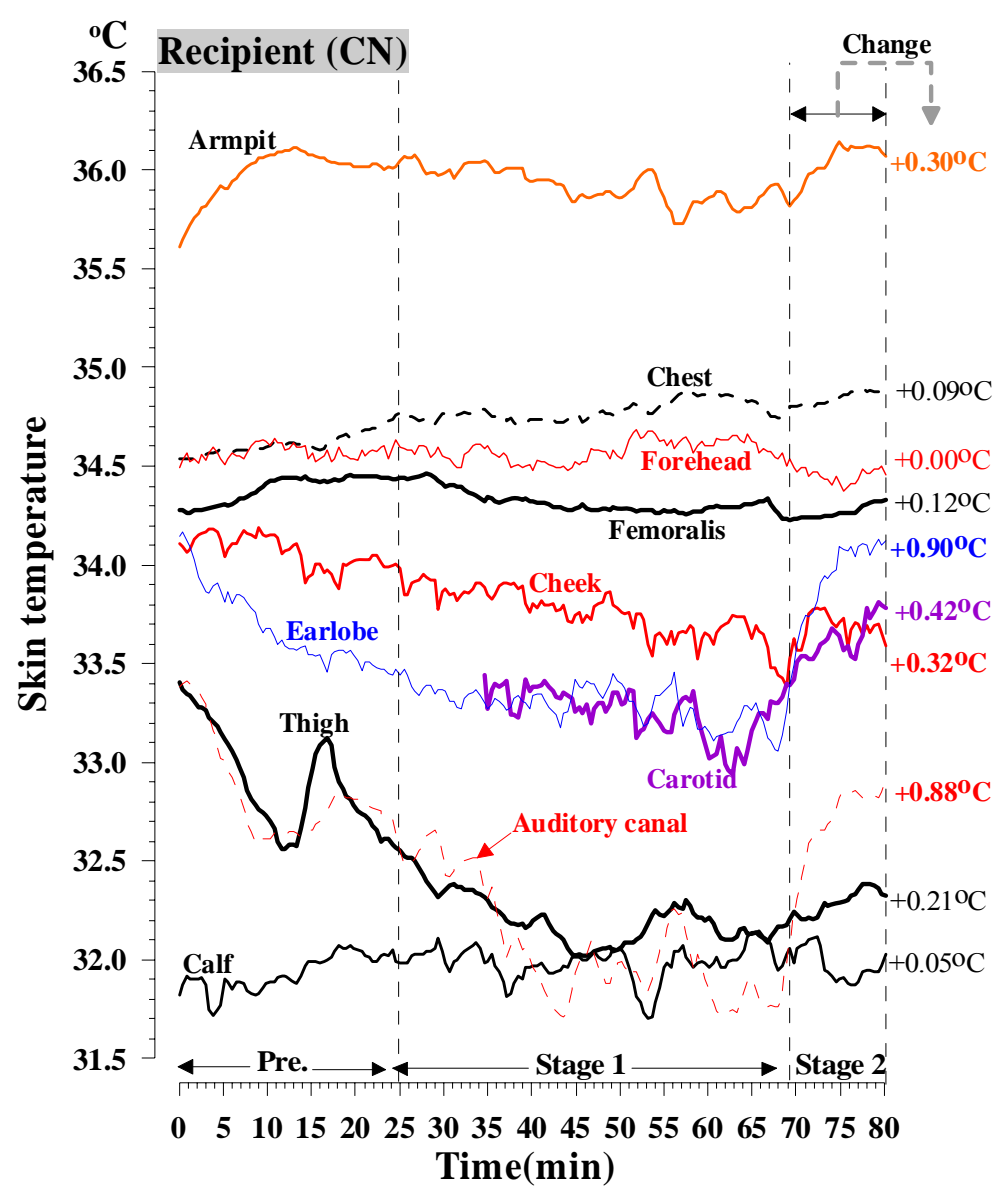

Fig. 5. Local skin temperatures of the Recipient across stages.

\section{Subjective sensations}

Subject ratings of Overall Thermal Sensation and Overall Thermal Comfort indicated that both the Recipient and the Donor showed a decrease in perception of cold from Stage 1 to Stage 2, and a lesser perception of discomfort. These ratings show that the sharing of heat had a salutary effect on the chilled Recipient (Figure 6).

\section{(Delete Overall Skin Wetness Sensation)}




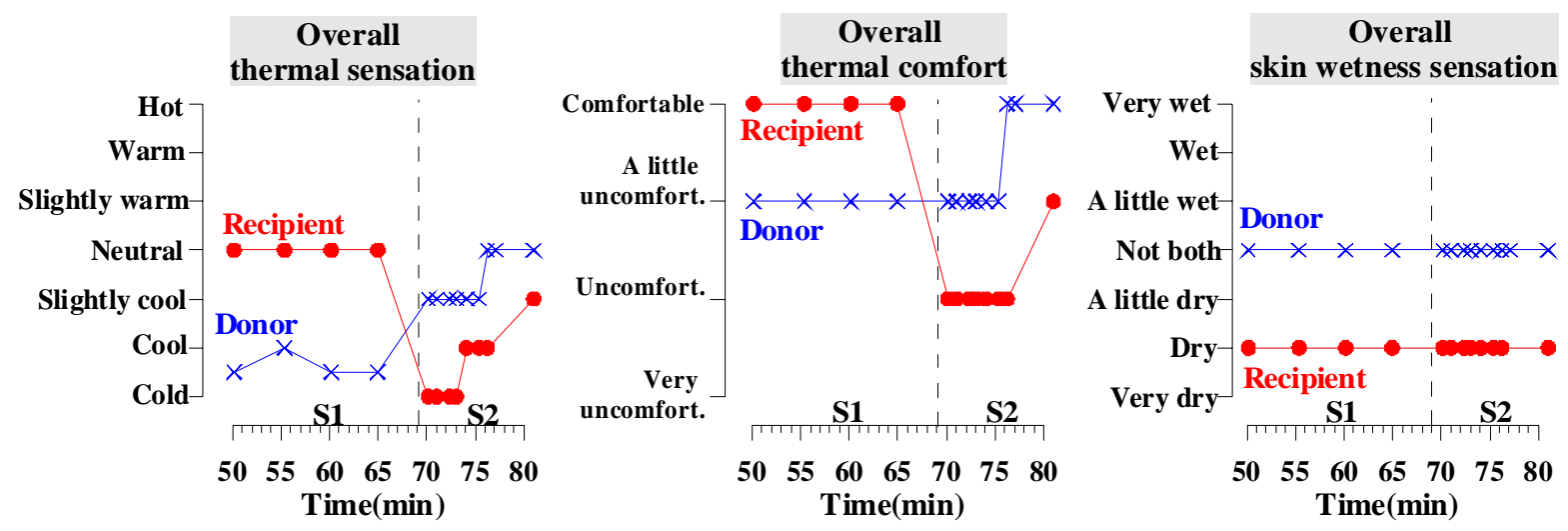

Fig. 6. Regional and overall thermal sensations of the Recipient and the Donor.

\section{Condition 2. Moderate exercise of the Donor and Recipient Cooling at rest}

\section{Heat flow}

Change Figure????. Water temperature in the outlet file between Donor and Recipient in the period of heat exchange change from $18.6^{\circ} \mathrm{C}$ to $24.2^{\circ} \mathrm{C}$ on the surface of the Recipient. It can be noted that this change initiates a chain of temperature changes in the core, and on the finger and skin surface (Figures 7, 8, 9, 11)

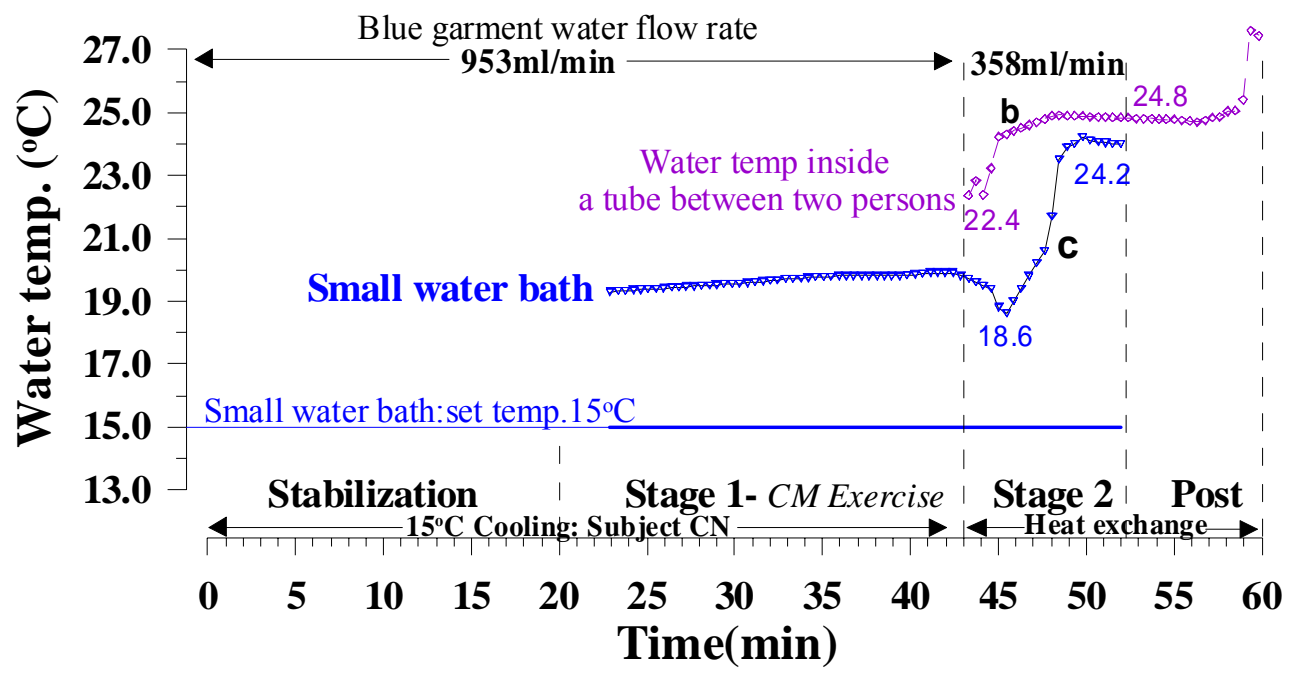

Fig. 7. Change in water temperature in the water file between the garments of the Recipient and Donor.

Delete other parts of the figure

\section{Core temperature}


There was little change in $\mathrm{T}_{\mathrm{re}}$ of the Recipient through the entire period of Stages 1-2 $\left(0.07^{\circ} \mathrm{C}\right)$; simultaneously, $\mathrm{T}_{\mathrm{re}}$ of the Donor, under exercise conditions, increased by $0.5^{\circ} \mathrm{C}$ in Stage 1 and decreased in Stage 2 by $0.2{ }^{\circ} \mathrm{C}$ due to the sharing of heat with the Recipient. (Figure 8).

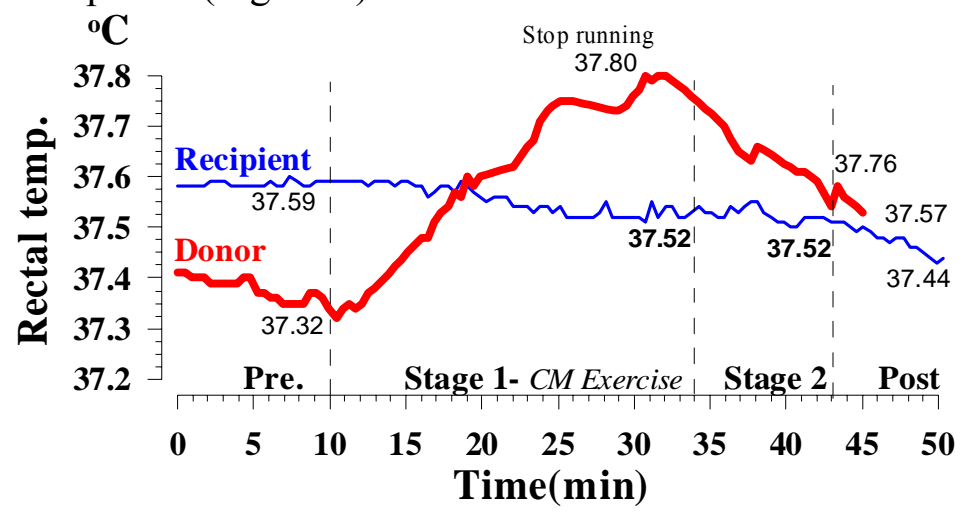

Fig. 8. Tre of Recipient and Donor across stages.

Delete the Stop running, CM exercise words from the figure. It's already clear what's happening. Same for the rest of these figures.

\section{Finger temperature}

The $\mathrm{T}_{\text {fing }}$ dynamic demonstrates a similar decreasing trend in both subjects. This indicates that heat exchange between the two participants is occurring through the body surface and continues during $10 \mathrm{~min}$ of Stage 2. This indicates that the heat exchange does not significantly change the deep tissues of the body core and the distal part of the extremities.

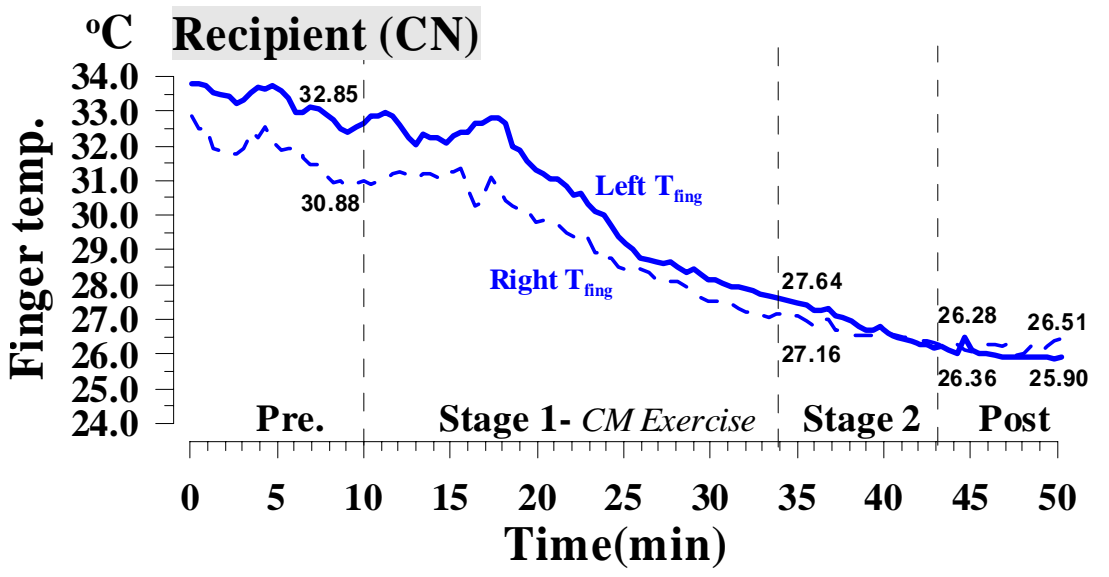

Fig. 9. Finger temperature across stages in Condition 2 Donor moderate exercise.

\section{Skin temperatures}

Skin temperature dynamics of the Recipient changed significantly during the period of heat transfer from one person to the other, especially on the lower extremities and the 
earlobe. Other skin temperatures were relatively stable, showing a small tendency to increase (Figure 10).

Delete upper 4 lines

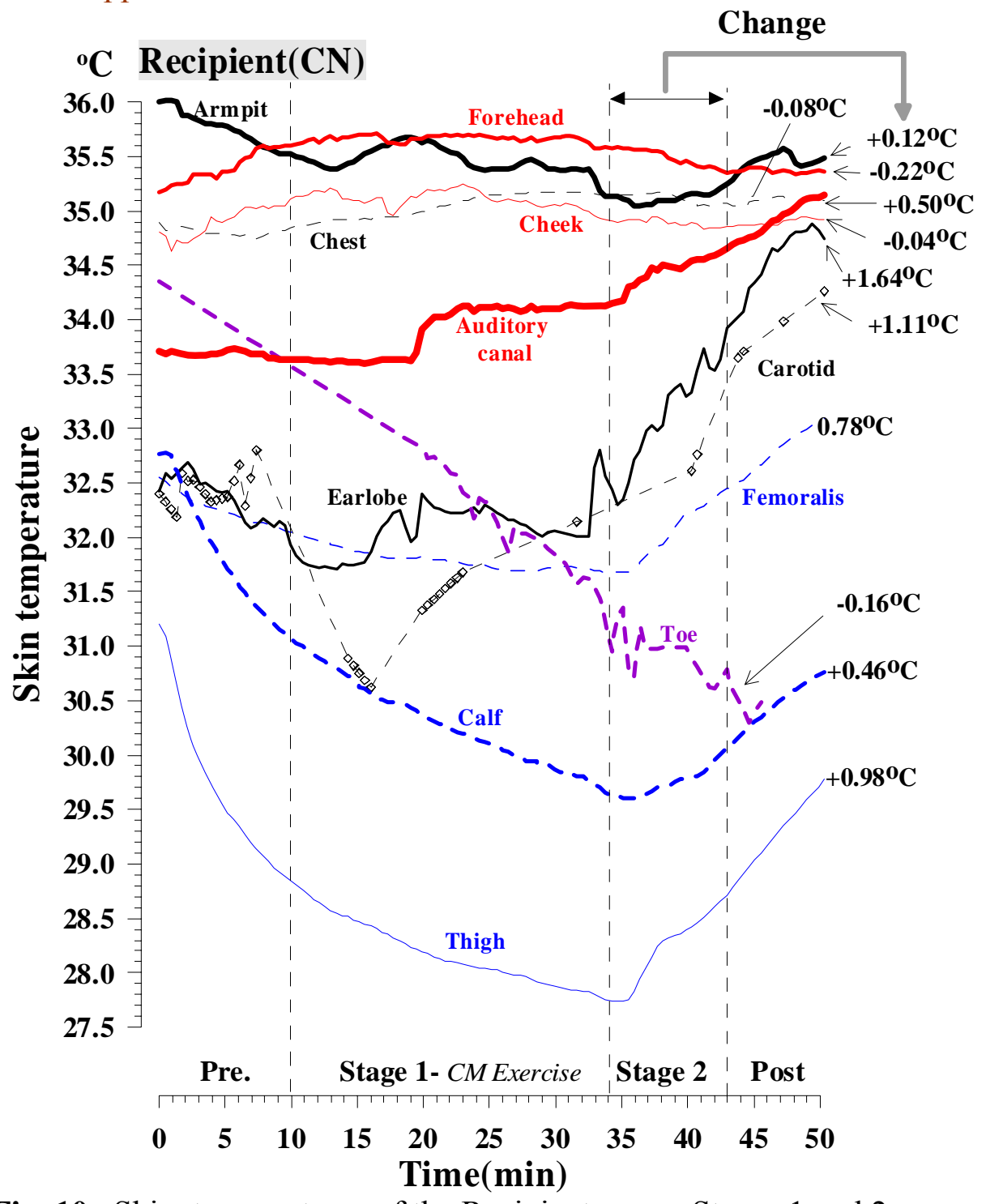

Fig. 10. Skin temperatures of the Recipient across Stages 1 and 2. 


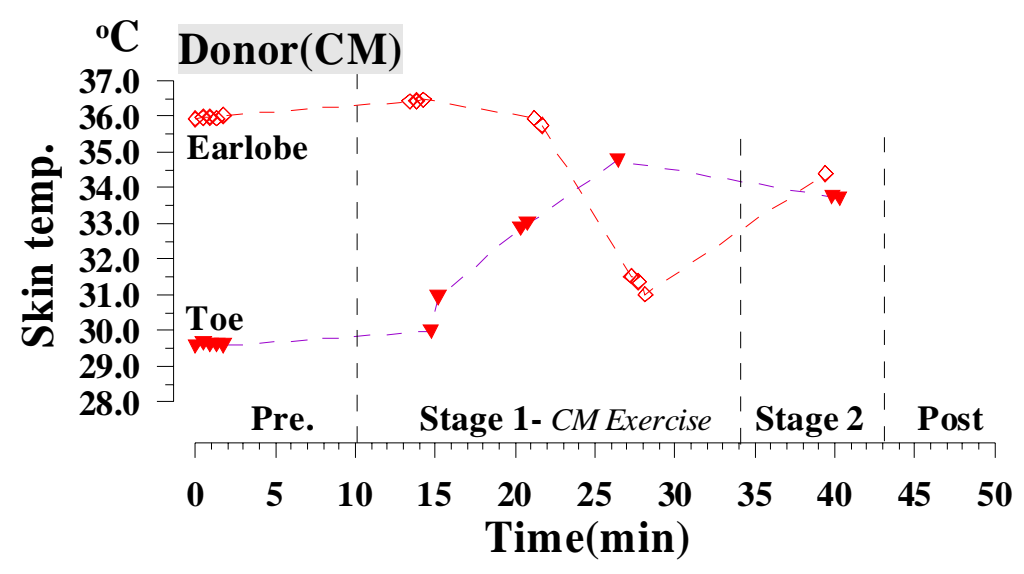

Fig. 11. Local skin temperature of the Donor across Stages 1 and 2.

\section{CONCLUSION}

These pilot evaluations suggest that it is possible to share heat between two persons through files of circulating water in the liquid cooling/warming garments. Potentially, this procedure has practical application not only for planetary exploration, but on Earth as well in extreme environments. The findings showed that the capability of heat sharing in the donor comfort condition is not great because the donor has only base metabolic heat which in normal conditions does not exceed more than $100 \mathrm{kcal}$. Therefore, the heat of the donor passing to the recipient's body surface is capable of changing only skin temperature in certain body areas, and does not affect the thermal status of the core and periphery of the limbs. In the situation in which the donor's metabolic rate was increased under the Condition 2 exercise protocol, this enabled an increase in the temperature of the water circulating in the cooling/warming garment and thus transferred through the file to the recipient. This transfer of heat helps to stabilize the temperature of the body surface of the recipient and provides support to stabilize the temperature of the lower extremities. It is possible that with an increase in the intensity of physical exertion by the donor and increasing the duration of heat exchange between the two participants, there will be an enhancement of thermoregulation and stabilization of thermal balance of the recipient. Further more comprehensive studies are necessary to follow through with the concepts and findings of this pilot/probe exploration.

\section{References}

Koscheyev, V.S., Leon, G.R., Coca, A., \& Treviño, R.C. (2005). Redirection of biological heat from head to fingers during a body cooling event. Aviation, Space, and Environmental Medicine, 76, 828-832. 